\title{
Serum level of endothelial markers in patients with psoriasis vulgaris with or without arteriogenic erectile dysfunction.
}

\author{
Elsayed M. Zayed, ${ }^{1}$ MSc, Essam Bakr Abdel Aal, ${ }^{1}$ MD, Ahmed Rashad Elshahid, ${ }^{1}$ MD,
} Nabil Fathy Ismail, ${ }^{1}$ MD.

\section{* Corresponding Author: \\ Elsayed M. Zayed \\ Sayedmzayed@gmail.com}

Received for publication

September 11, 2021; Accepted

January 12, 2022; Published

online January 12, 2022.

Copyright The Author published by Al-Azhar University, Faculty of Medicine, Cairo, Egypt. Users have the right to read, download, copy, distribute, print, search, or link to the full texts of articles under the following conditions: Creative Commons AttributionShare Alike 4.0 International Public License (CC BY-SA 4.0).

doi: $10.21608 /$ aimj.2022.95508.1572.

${ }^{I}$ Dermatology Department, Faculty of Medicine, Al-Azhar University,

Cairo, Egypt.

\begin{abstract}
Background: Psoriasis is a widespread systemic chronic cell immunemediated inflammatory condition of the nails, skin, and joints that affects adults and children of different age groups. The inability to initiate and/or sustain an adequate erection for satisfactory sexual performance is known as erectile dysfunction (ED).

Aim of the study: The objective of this research is to measure serum ICAM-1 and VCAM-1 in the periphery and penile blood to evaluate endothelial function in psoriasis patients with or without arteriogenic erectile dysfunction thus can serve as an early marker of endothelial cell injury and their possible future role in management of these disorders.

Patients and Methods: Thirty patients with psoriasis and arteriogenic $\mathrm{ED}$, thirty patients with arteriogenic ED and thirty healthy donors were subjected for measuring serum ICAM-1 and VCAM-1 levels in the periphery and penile blood as well as assessment of erectile function by Penile Dopplex ultrasound.

Results: Psoriatic patients with arteriogenic ED had significantly higher serum ICAM-1 and VCAM-1 levels (more in penile than peripheral blood samples) than patients with arteriogenic ED only. And the difference reached high statistical significance between psoriatic patients with ED and healthy controls.

Conclusion: In psoriasis and erectile dysfunction, measurements of ICAM-1 and VCAM-1 in the serum could be used as indicators of clinical treatment and outcome, allowing for early therapy and avoidance of endothelial damage.
\end{abstract}

Keywords: Psoriasis; Arteriogenic ED; ICAM-1; VCAM-1.

\section{INTRODUCTION}

Disclosure: The authors have no financial interest to declare in relation to the content of this article. The Article Processing Charge was paid for by the authors.

Authorship: All authors have a substantial contribution to the article.

Psoriasis has been a systemic, chronic, cell-mediated inflammatory disorder which impacts the nails, skin, and joints in different age groups. ${ }^{1}$

Psoriasis-related vascular changes are caused by elevated expression of vascular endothelial growth factor (VEGF). ${ }^{2}$

Upon stimulation of cytokines, adhesion molecules (ICAM-1 and VCAM-1) are upregulated over the vascular endothelium, allowing transmigration of leukocytes into tissues. ${ }^{3}$

Erectile dysfunction (ED) is described as the failure to achieve and/or sustain a firm enough erection to engage in sexual intercourse satisfactorily. ${ }^{4}$

Endothelial dysfunction is considered the main pathophysiologic event of arteriogenic ED 
Inclusion criterion: 30 patients with psoriasis and arteriogenic ED, 30 patients with arteriogenic ED and 30 healthy donors as control ranged from 20 to 60 years with stable marital status

Exclusion criteria: age $<20$ or $>60$ years, Psychogenic, venogenic and neurogenic erectile dysfunction, Penile abnormalities, Penile prosthesis, Primary and secondary hypogonadism, Severe Systemic sclerosis, Severe chronic medical illness (liver and kidney diseases), Patients who have had a history of coronary heart disease or under treatment of IHD, Drugs as biological therapy, MTX and Acitretin and Phototherapy.

The following procedures were carried out on all of the patients: collection of general informations and history taking, consent from the patient, complete physical, dermatological and andrological examination, radiological diagnosis: Penile Dopplex ultrasound was performed, and serological diagnosis: for measuring serum ICAM-1 and VCAM-1 levels in peripheral and penile blood samples.

\section{RESULTS}

This study comprised 90 patients: 30 with psoriasis and arteriogenic ED, 30 with arteriogenic ED, and 30 healthy donors as controls.

Concerning age; Group 1 included 30 patients aged 29 to 59, with a mean of 45; Group 2 included 30 patients aged 29 to 59, with a mean of 47 ; and Group 3 included 30 patients aged 25 to 56 , with a mean of 41 (Table 1).

Concerning age, there were no statistically significant differences $(\mathrm{P}>0.05)$ between the three groups (Table 2).

\begin{tabular}{|c|c|c|c|c|c|c|}
\hline \multirow[t]{2}{*}{ Group } & \multirow[b]{2}{*}{$\mathrm{N}$} & \multicolumn{2}{|c|}{ Age (yrs) } & \multirow[t]{2}{*}{$\mathrm{X} 2$} & \multirow[t]{2}{*}{$P$ value } & \multirow[b]{2}{*}{ Sig. } \\
\hline & & Mean & Range & & & \\
\hline Psoriasis and Arteriogenic ED & 30 & 45 & $29-59$ & \multirow[b]{3}{*}{6.86} & \multirow{3}{*}{0.32} & \\
\hline Arteriogenic ED & 30 & 47 & $29-59$ & & & \multirow[b]{2}{*}{ NS } \\
\hline Control & 30 & 41 & $25-56$ & & & \\
\hline
\end{tabular}

Table 1: Comparison between the three groups according to age (Kruskal Wallis Test; NS= Non-Significant $\mathrm{P}>0.05)$.

$\begin{array}{lcccccccc}\text { Groups } & \mathrm{N} & \text { Min } & \text { Max } & \text { Mean } & \text { SD } & \text { X2 } & \text { P-value } & \text { Sig. } \\ \text { Groups A } & 30 & 70.00 & 5671.00 & 2316.52 & 1518.97 & & & \\ \text { Groups B } & 30 & 33.00 & 4120.00 & 2165.75 & 1342.98 & 19.45 & 0.000 & \text { S } \\ \text { Groups C } & 30 & 30.00 & 2153.00 & 819.36 & 632.12 & & & \end{array}$

Table 2: Comparison between the three groups according to peripheral ICAM-1. (Kruskal Wallis Test; $\mathrm{S}=$ Significant

$(\mathrm{P}<0.05)$.

There were statistically significant differences in the mean of peripheral ICAM-1 between the three groups $(\mathrm{P}<0.05)$ (Figure 1; Table 3).

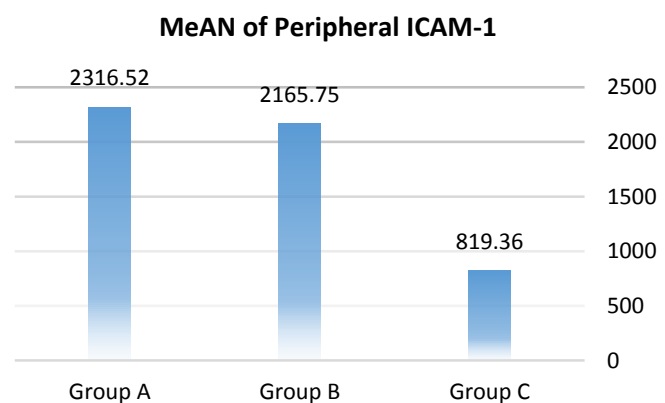

Fig 1: Comparison between the three groups according to Peripheral ICAM-1.

There were statistically significant differences in the mean of penile ICAM-1 between the three groups ( $\mathrm{P}$ $<0.05$ ) (Figure 2; Table 4).

\section{MEAN OF Penile ICAM-1}

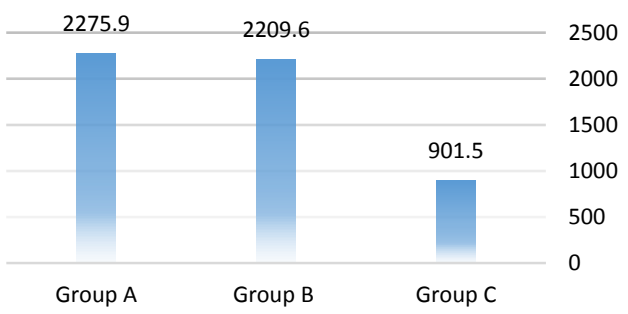

Fig 2: Comparison between the three groups according to Penile ICAM-1.

There were statistically significant differences in the mean of peripheral VCAM-1 between the three groups $(\mathrm{P}<0.05)$ (Figure 3; Table 5).

There were statistically significant differences in the mean of penile VCAM-1 between the three groups ( $\mathrm{P}$ $<0.05$ ) (Figure 4; Table 6).

There were statistically significant differences in the mean of PSV between the three groups $(\mathrm{P}<0.05)$ (Figure 5; Table 7). 


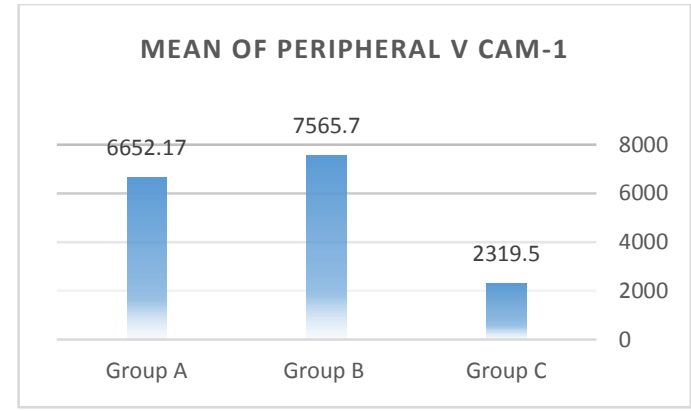

Fig 3: Comparison between the three groups according to Peripheral VCAM-1.

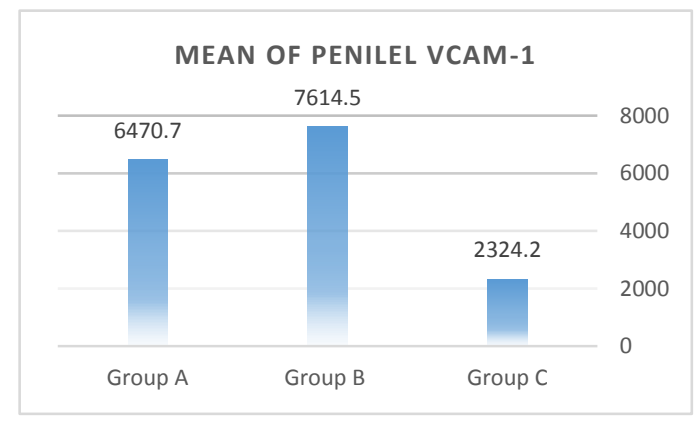

Fig 4: Comparison between the three groups according to Penile VCAM-1

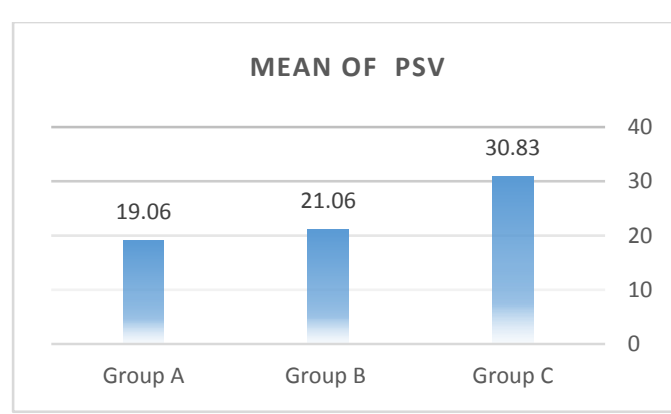

Fig 5: Comparison between the three groups according to Penile VCAM-1

\section{DISCUSSION}

Psoriasis is a widespread systemic chronic immunemediated inflammatory disease which affects both children's and adults' skin, nails, joints, and other organs. $^{7}$

Genetics play a significant part in psoriasis pathogenesis, and it is affected by other factors as well. It is characterized by altered differentiation and hyperproliferation of keratinocytes, infiltration by Tlymphocyte, and changes in dermal blood vessels. ${ }^{8}$

Pathological findings in psoriasis are not confined only to the skin, but also affect other sites. ${ }^{9}$

\begin{tabular}{lllllllll}
\hline Groups & $\mathrm{N}$ & Min & Max & Mean & SD & X2 & P-value & Sig. \\
Groups A & 30 & 77.00 & 5932.00 & 2275.9 & 1594.9789 & & & \\
Groups B & 30 & 41.00 & 4147.00 & 2209.6 & 1360.232 & 17.06 & 0.00 & S \\
Groups C & 30 & 31.00 & 2334.00 & 901.5 & 685.85 & & & \\
\hline
\end{tabular}

Table 3: Comparison between the three groups according to Penile ICAM-1. (Kruskal Wallis Test; S= Significant $(\mathrm{P}<0.05)$.

\begin{tabular}{lllllllll}
\hline Groups & $\mathrm{N}$ & Min & Max & Mean & SD & X2 & P-value & Sig. \\
Groups A & 30 & 90.00 & 13590 & 6652.17 & 4406.95 & & & \\
Groups B & 30 & 190.0 & 14543 & 7565.17 & 4506.045 & 21.93 & 0.000 & S \\
\hline Groups C & 30 & 97.00 & 7124 & 2319.50 & 2325.861 & & & \\
\hline
\end{tabular}

Table 4: Comparison between the three groups according to Peripheral VCAM-1. (Kruskal Wallis Test; $\mathrm{S}=$ Significant $(\mathrm{P}<0.05)$.

\begin{tabular}{lllllllll}
\hline Groups & $\mathrm{N}$ & Min & Max & Mean & SD & X2 & P-value & Sig. \\
Groups A & 30 & 107.00 & 13596.00 & 6470.7 & 4492.7921 & & & \\
Groups B & 30 & 193.00 & 14607.00 & 7614.5 & 4515.0938 & 15.60 & 0.001 & S \\
\hline Groups C & 30 & 93.00 & 7138.00 & 2324.2 & 2326.2778 & & & \\
\hline
\end{tabular}

Table 5: Comparison between the three groups according to Peripheral VCAM-1. (Kruskal Wallis Test; S= Significant $(\mathrm{P}<0.05)$.

$\begin{array}{lllllllll}\text { Groups } & \mathrm{N} & \mathrm{Min} & \mathrm{Max} & \text { Mean } & \text { SD } & \text { X2 } & \text { P-value } & \text { Sig. } \\ \text { Groups A } & 30 & 14.00 & 23.00 & 19.0667 & 2.53164 & & & \\ \text { Groups B } & 30 & 17.00 & 24.00 & 21.0667 & 2.09981 & 49.8 & 0.000 & \mathrm{~S} \\ \text { Groups C } & 30 & 26.00 & 35.00 & 30.8333 & 2.58755 & & & \end{array}$

Table 6: Comparison between the three groups according to PSV. (Kruskal Wallis Test; $\mathrm{S}=$ Significant $(\mathrm{P}<0.05)$. 


\begin{tabular}{|c|c|c|c|}
\hline Group A & & PASI & PSV \\
\hline \multirow[t]{4}{*}{ Peripheral ICAM-1 } & & 0.614 & -0.640 \\
\hline & & & \\
\hline & P-value & 0.000 & 0.000 \\
\hline & S & $\mathrm{S}$ & $\mathrm{S}$ \\
\hline \multirow[t]{3}{*}{ Penile ICAM-1 } & Rho & 0.594 & -0.675 \\
\hline & P-value & 0.001 & 0.000 \\
\hline & $\mathrm{S}$ & $\mathrm{S}$ & $S$ \\
\hline \multirow[t]{3}{*}{ Peripheral VCAM-1 } & Rho & 0.763 & -0.757 \\
\hline & P-value & 0.000 & 0.000 \\
\hline & $\mathrm{S}$ & $\mathrm{S}$ & S \\
\hline \multirow[t]{3}{*}{ Penile VCAM-1 } & Rho & 0.729 & -0.690 \\
\hline & $\mathrm{P}$-value & 0.000 & 0.000 \\
\hline & S & $\mathrm{S}$ & S \\
\hline \multirow{3}{*}{ PASI } & Rho & -- & -0.730 \\
\hline & P-value & -- & 0.000 \\
\hline & $\mathrm{S}$ & -- & $S$ \\
\hline
\end{tabular}

Table 7: Correlation between different parameters among group A (Psoriasis with Arteriogenic ED). (X2: Chisquare test; NS: p-value > 0.05 is considered non-significant; S: p-value < 0.05 is considered significant; HS: pvalue $<0.001$ is considered highly significant).

\begin{tabular}{|c|c|c|}
\hline Group B & & PSV \\
\hline \multirow[t]{4}{*}{ Peripheral ICAM-1 } & & -0.740 \\
\hline & & \\
\hline & P-value & 0.000 \\
\hline & $\mathrm{S}$ & $\mathrm{S}$ \\
\hline \multirow[t]{3}{*}{ Penile ICAM-1 } & Rho & -0.735 \\
\hline & $\mathrm{P}$-value & 0.000 \\
\hline & $\mathrm{S}$ & $\mathrm{S}$ \\
\hline \multirow[t]{3}{*}{ Peripheral VCAM-1 } & Rho & -0.885 \\
\hline & $\mathrm{P}$-value & 0.000 \\
\hline & $\mathrm{S}$ & S \\
\hline \multirow[t]{3}{*}{ Penile VCAM-1 } & Rho & -0.888 \\
\hline & $\mathrm{P}$-value & 0.000 \\
\hline & $\mathrm{S}$ & S \\
\hline
\end{tabular}

Table 8: Correlation between different parameters among group B (Arteriogenic ED). (X2: Chi-square test; NS: pvalue $>0.05$ is considered non-significant; $\mathrm{S}$ : $\mathrm{p}$-value $<0.05$ is considered significant; HS: $\mathrm{p}$-value $<0.001$ is considered highly significant).

Many illnesses that co-occur with psoriasis, like insulin resistance, atherogenesis, atherosclerosis, dyslipidemia, hypertension, obesity, diabetes mellitus (DM) type 2, and metabolic syndrome, may be caused by the pro-inflammatory cytokines generated during chronic inflammation. ${ }^{10}$

There is increased expression of IL-1, L-6, IL17, IL22 and $\mathrm{TNF}-\alpha$ in psoriatic plaques. The primary cytokine is called IL-1, since it can trigger inflammation independently through number of mechanisms. $^{11}$

The vascular changes in psoriasis are caused by increased expression of vascular endothelial growth factor (VEGF). ${ }^{2}$

Once cytokine stimulation occurs, ICAM-1 and VCAM-1 become overexpressed on the vascular endothelium, allowing leucocytes to transmigrate into tissues. $^{12}$
The inability to initiate and/or sustain a rigid enough erection to allow satisfactory sexual intercourse is known as erectile dysfunction (ED). ${ }^{13}$

Metabolic syndrome (MetS) is a complex entity composed of multiple intermingled variables such as dyslipidemia, insulin resistance, endothelial dysfunction, central adiposity, and atherosclerosis, minimal inflammatory process, and in males, low testosterone levels. MetS has been linked to erectile dysfunction as one of many urological diseases. ${ }^{14}$

Endothelial dysfunction, ED, and aging all have a close association. In addition, subclinical endothelial dysfunction disease may be first presented by ED before the emergence of cardiovascular disease or any risk factor for cardiovascular disease ${ }^{15}$

Endothelial dysfunction is a critical occurrence in the pathophysiology of arteriogenic ED, and individuals having penile vascular dysfunction also experience endothelial dysfunction in other vascular pathways. ${ }^{16}$ 
Endothelial dysfunction, which is hampered by inflammatory conditions and elevated oxidative stress, is a critical occurrence in the pathophysiology of ED. ${ }^{17}$

Levels of soluble ICAM-1 and VCAM-1 were considerably greater in males having $\mathrm{ED}$ but no cardiovascular disease. ${ }^{6}$

This study included 90 men who attended to the dermatology and andrology outpatient clinics at (AlHussien and Bab Al-Shariah University Hospitals); 30 patients with Psoriasis and arteriogenic ED, 30 patients with arteriogenic ED and 30 healthy sexually active volunteers of matched age as a control group.

All men volunteered to participate in this study were married and have only one sexual partner. Subjects were comprehensively evaluated and asked to answer the five-item version of International Index of Erectile Function (IIEF-5) questionnaire as a method to diagnose and classify ED. All Psoriatic patients were evaluated by (PASI) score. All subjects had through medical history and full physical assessment. All ED patients investigated by penile duplex. The serum level of ICAM-1 and VCAM-1 was measured for all individuals using specific enzyme-linked immunosorbent assay (ELISA) technique.

Some researchers discovered that patients with psoriasis vulgaris had higher serum concentrations of soluble ICAM-1 (sICAM-1) molecules. They linked it to the disease's severity (PASI score) ${ }^{18-20}$ and this comes in an agreement to our study in peripheral blood, others, however, found no increase in sICAM1 molecules following UVB and PUVA treatments ${ }^{21-}$ ${ }^{22}$ which comes in disagreement to our study.

Another study that was carried out and showed that psoriatic patients had greater serum sICAM-1 levels than healthy donors, which is consistent with our study. ${ }^{23}$

Soluble ICAM-1 and VCAM-1 levels were considerably greater in males having ED but no cardiovascular disease ${ }^{6}$ and this in agreement with our study in which serum ICAM-1 and VCAM-1 are elevated in both groups $\mathrm{A}$ and $\mathrm{B}$.

\section{CONCLUSION}

Psoriatic patients with arteriogenic ED had significantly higher serum ICAM-1 and VCAM-1 levels than arteriogenic ED patients only in this study. And the difference reached high statistical significance between psoriatic patients with ED and healthy controls. Serum ICAM-1 and VCAM-1 levels were further increased when ED was associated with psoriasis, suggesting a more severe course of ED in these patients.

This study's findings imply that ICAM-1 and VCAM-1 as endothelial markers play a detrimental role in erectile function, and indicate that they may be implicated in the pathogenic process of $\mathrm{ED}$, and could be utilized as an indicator to monitor the severity and progress of the disease. When ED and Psoriasis coexist, these marker levels are higher than when ED is present alone. These findings support that this factor could be a general inflammatory marker of endothelial damage, and emphasize the pathophysiological involvement of ICAM-1, VCAM1, and endothelial dysfunction in ED pathogenesis.

\section{REFERENCES}

1. Bronckers, Paller, van Geel, et al. Psoriasis in children and adolescents: Diagnosis, management and comorbidities. Pediatr Drugs. 2015; 17: 37384.

2. Nestle FO, Kaplan DH and Barker J. Psoriasis. $N$ Engl J Med. 2009; 361:496-09.

3. Bressan AL, Bicciani BLS, Azulay-Abulafia L, et al. Evaluation of ICAM-1 expression and vascular changes in the skin of patients with plaque, pustular, and erythrodermic psoriasis. Int. J. Dermatol. 2018; 57, 209-16.

4. Albersen M, Yafi FA, Jenkins L, et al. Erectile dysfunction. Nature Reviews Disease Primers. 2016; 2: 16003 .

5. Garshick MS, Barrett $T$, Wechter $T$, et al. Inflammasome Signaling and Impaired Vascular Health in Psoriasis. Arter. Thromb. Vasc. Biol. 2019;39, 787-98.

6. Bocchio M, Desideri G, Scarpelli P, et al. Endothelial cell activation in men with erectile dysfunction without cardiovascular risk factors and overt vascular damage. J Urol. 2004; 171:1601-4.

7. Bronckers, Paller, van Geel, et al. Psoriasis in children and adolescents: Diagnosis, management and comorbidities. Pediatr Drugs. 2015; 17: 37384.

8. Sereflican, Goksugur, Bugdayci, et al. Serum visfatin, adiponectin, and tumor necrosis factor alpha (TNF- $\alpha$ ) levels in patients with psoriasis and their correlation with disease severity. Acta Dermato Venerol Croat. 2016; 24 (1): 13-9.

9. Rajappa, Rathika, Munisamy, et al. Effect of treatment with methotrexate and coal tar on adipokine levels and indices of insulin resistance and sensitivity in patients with psoriasis vulgaris. J Eur Acad Dermatol Venereol. 2015; 29: 69-76.

10. Dikbas, Tosun, Cemal, et al. Serum levels of visfatin, resistin and adiponectin in patients with psoriatic arthritis and associations with disease severity. Intl J Rheum Dis. 2016; 19 (7): 672-7.

11. Dowlatshahi EA, van der Voort EA, Arends LR et al. Markers of systemic inflammation in psoriasis: a systematic review and meta-analysis. Br J Dermatol. 2013; 169:266-82.

12. Michael SG, Tessa JB, Todd W, et al. Inflammasome signaling and impaired vascular health in psoriasis. Arteriosclerosis, Thrombosis and vascular biology. 2019; 39:787-98.

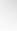
(n) 
13. Muneer A, Kalsi J, Nazareth I, et al. Erectile Dysfunction. BMJ. 2014;10.

14. Hatzimouratidis K, Amar E, Eardley I, et al. Guidelines on male sexual dysfunction: erectile dysfunction and premature ejaculation. European urology. 2010; 57: 804-14.

15. Gorbachinsky I, Akpinar H and Assimos DG. Metabolic syndrome and urologic diseases. Reviews in urology. 2010; 12:157.

16. Peter JL, Christopher DA, Suowen Xu, et al. Endothelial dysfunction and cardiovascular diseases: History and analysis of the clinical utility of the relationship. Biomedicines. 2021; 9, 699.

17. Trepels, Zeiher and Fichtlscherer. The endothelium and inflammation. Endothelium. 2012; 13:423-9.

18. Long JW, Tao J, Pi XM, et al. Effect of narrowband UVB phototherapy on soluble cell adhesion molecules in patients with psoriasis vulgaris. The journal of international medical research. 2010; 1507-12.

19. Ameglio F, Bonifati C, Carducci $M$, et al. Influence of PUVA and UVB Radiation on Expression of ICAM-1 and VCAM-1 Molecules in Psoriasis Vulgaris. Acta Derm Venerol. 1994; 186-19.

20. Carduccim, Mussi A, Bonifati C, et al. Influence of PUVA and UVB Radiation on Expression of ICAM-1 and VCAM-1 Molecules in Psoriasis Vulgaris. Arch Dermatol Res. 1994; 286-20.

21. Petersen AA, Bech-Thomsen N, Mainolfi EA, et al. Influence of PUVA and UVB Radiation on Expression of ICAM-1 and VCAM-1 Molecules in Psoriasis Vulgaris. Acta Derm Venereol. 1997; 377-98.

22. Kowalzick L, Biladu H, Neuber $K$, et al. Influence of PUVA and UVB Radiation on Expression of ICAM-1 and VCAM-1 Molecules in Psoriasis Vulgaris. Arch Dermatol Res. 1993; 285-526.

23. Gangemi S, Merindino RA, Guarneri F, et al. Serum levels of interleukin-18 and s-ICAM-1 in patients affected by psoriasis: Preliminary considerations. JEADV. 2003; 17: 42-6. 